ISSN: 2162-3104 Print/ ISSN: 2166-3750 Online

Volume 7, Issue 2 (2017), pp. 204-228

(c) Journal of International Students

http://jistudents.org/

\title{
Acculturative Stress and Adjustment Experiences of Greek International Students
}

\author{
Mixalis Poulakis \\ Craig A. Dike \\ Amber C. Massa \\ University of Indianapolis (USA)
}

\begin{abstract}
This study investigated eight Greek international college students' experiences of acculturation and acculturative stress at a mid-western university in the United States. Semi-structured interviews were conducted with participants and Consensual Qualitative Research methodology was utilized for data analysis to identify contextual themes and domains expressed by participants. Seven domains relevant to extant literature were revealed: presojourn perceptions of the United States; postsojourn perceptions of the United States; acculturative stress problems in the United States; coping strategies for acculturative stress problems; peer and family networks: English language usage and difficulties; and cultural concerns regarding the United States or native country. Implications, areas for future research, and the study's limitations are also discussed.
\end{abstract}

Keywords: International Student, Greek, Acculturation, Adjustment, Acculturation, Acculturative stress

The United States has always been home, both permanent and temporary, to a diverse population originating from various countries. International students greatly contribute to this diverse population. A recent study reported 886,052 international students enrolled in higher education institutions in the United States during the 2013-2014 academic year, an 8.2\% increase from the previous academic year (Institute of International Education, 2014). With the support of the government, colleges and universities continue to actively recruit and encourage international students to study here due to their economic contributions, their promotion of global consciousness and the exposure they provide to a variety of 
cultural experiences for native students (Altbach, 2004a). Contributing to this increasing number are Greek students. However, there is a paucity of research examining Greek students' experiences in their host countries. Specifically, little research exists regarding their acculturation and acculturative stress, two common and important experiences amongst international students. As Greek students continue to study abroad, it becomes increasingly important to examine their acculturation process, and subsequently, their acculturative stress experiences. By doing so, rich information can be gathered on this group's specific experiences and needs as well as information that can potentially contribute the extant body of literature detailing international students' acculturative experience, providing avenues for discussion and intervention on how to decrease acculturative stress.

\section{LITERATURE REVIEW}

\section{Acculturation and Acculturative Stress}

As the number of international students attending universities steadily rises each year, mental health professionals working in these institutions must become better prepared for what experiences these students bring with them. Acculturation is one such experience. Acculturation refers to the process of cultural and psychological change when two or more different cultural groups have contact with one another (Berry, 2003). Various strategies may be employed in an attempt to adapt to a new culture, including integration, assimilation, separation, and marginalization (Berry, 2006). Additionally, when conflict and stress are encountered during the acculturative process and the individual judges these situations as problematic, but surmountable and controllable, acculturative stress is an appropriate conceptualization (Berry, 2006; Berry, Kim, Minde, \& Mok, 1987; Berry, 1980). During this scenario, individuals experience alterations in their lives that conflict with their original cultural understanding of how to live. Those who can assimilate and integrate two differing cultures will experience less acculturative stress (Mori, 2000; Winkelman, 1994). Those who employ marginalization or separation may experience increased levels of acculturative stress and even clinical depression (Constantine, Okazaki, \& Utsey, 2004).

Physical, psychological and social manifestations of acculturative stress can occur, leading to a multitude of mental health problems (Constantine, Okazaki, \& Utsey, 2004). Any one problem in the various areas involved in acculturation can lead to acculturative stress. These experiences include decreased mental health (such as depression or anxiety), increased psychosomatic symptoms, culture shock, lack and loss of social support, prejudice, discrimination, alienation, language barriers, and role confusion (Berry et al., 1987; Mori, 2000). While a large body of research has been 
devoted to studying adjustment and acculturation in international populations, only a small segment has been devoted to acculturative stress, and an even smaller sample to acculturative stress in international students (Constantine et al., 2004; Constantine, Anderson, Berkel, Caldwell, \& Utsey, 2005b; Constantine, Kindaichi, Okazaki, Gainor, \& Baden, 2005c; Poyrazli, Kavanaugh, Baker, \& Al-Timimi, 2004; Abe, Talbot, \& Geelhoed, 1998; Hayes \& Lin, 1994; Olaniran, 1993; Pedersen, 1991).

\section{Acculturative Stress in International Student Populations}

There are both shared and unique factors amongst international students affecting their acculturative process and consequently, leading to acculturative stress. One shared factor includes residency. International students, as a minority, are different than typical ethnic or immigrant minorities due to two main reasons: (1) they are not permanent residents of the United States and (2) they have chosen a transitional living environment to learn a skill set prior to returning to their native origin (Mori, 2000). Their time in their host country is usually short and temporary versus a permanent stay. Yet these students are still expected to acculturate (Yoon \& Portman, 2004). Due to the temporary distance from family and friends, international students are more likely to have a social support network made up of peers from the same-ethnic group (Furnham \& Bochner, 1982, Thomas \& Althen, 1989). International students may also experience academic, financial, interpersonal/intrapersonal problems, and language barriers comparable to levels experienced by refugees (Berry \& Kim, 1988). Difficulty with the dominant language and limited affiliation with American culture and customs may lead to academic, psychological, and social difficulties (Mori, 2000; Pedersen, 1991). For example, studies have shown that students who wish to maintain a more culturally traditional lifestyle, are less fluent with the English language, have little contact with the dominant culture, and are not apart of the racial majority are more likely to experience acculturative stress and adjustment difficulties (Farver, Narang, \& Bhadha, 2002; Ghuman, 1997). In contrast, proficiency in the English language, positive perceptions of social acceptance, and a longer period of residency in the United States have been associated with more successful cultural adjustment and less acculturative stress (Sodowsky \& Plake, 1992). Poyrazli et al. (2004) also found that international students who were primarily socialized with non-Americans reported higher levels of acculturative stress than those who socialized with Americans. Students who socialized with both groups reported less acculturative stress and more support than those who socialized strictly with Americans.

Despite these shared factors, specific problems may also be heterogeneous and vary in intensity and commonality depending on a student's country and culture of origin (Poyrazli et al., 2004; Hayes \& Lin, 1994; Berry \& Kim, 1988; Sykes \& Eden, 1985). Surprisingly, not only 
does the available literature generally fail to account for such differences, there is also relatively little literature examining acculturative stress in several international student populations, including Greek students.

\section{Gaps in Research}

There is a consistent pattern of overgeneralization of research findings within the acculturation literature. Many studies attempt to generalize results of studied groups to all groups of international students because of a lack of research with certain populations. One such example is a study that examined six international students of two different nationalities and claimed from its results that all international students have a preference for directive counseling styles versus nondirective counseling styles (Yau, Sue, \& Hayden, 1992). Researchers must remember to utilize caution in attempting to generalize findings to an entire population, especially understudied ones, when limitations such as small sample sizes exist (Yoon \& Portman, 2004). It is more accurate to state that some characteristics may be shared because of common experiences as international students. However, there may also be differences based solely on individual cultural groups (Yoon \& Portman, 2004; Pedersen, 1997; Sodowsky \& Plake, 1992).

This realization by the cross-cultural psychological community has resulted in a number of studies directed at specific cultural groups and ethnicities in order to further our understanding, not of international students in general, but the individual students coming to study at our institutions (Constantine et al., 2005b; Constantine et al., 2005c; Kurman, Eshel, \& Zehavi, 2005; Constantine, Okazaki, \& Utsey, 2004; Ghosh \& Lu, 2003). With this orientation toward research, more culturally specific claims and theories can be made. By studying the individual impacts of our culture on others (and vice versa), we can begin to lay a foundation of research directed at benefiting educational institutions and the people who choose to study at them.

Additionally, while there is continuing research of acculturation with minority groups such as Asian, Hispanic, and African international student populations, there has been limited research regarding the acculturation of Caucasian immigrant ethnic groups (Ponterotto et al., 2001). Caucasian ethnic groups may be perceived as qualitatively different from people of color as they lack the history and ongoing prejudice/racism experienced by the latter. However, there is a great degree of heterogeneity within Caucasian ethnic groups (Ponterotto et al., 2001). And while European students account for the second largest student population studying in the United States (9.8\%; Institute of International Students, 2014), they are one of the least researched. Greek students, a specific population within the larger European student body and a Caucasian ethnic group, are also ranked highly in student migration (Lianos, Asteriou, \& Agiomirgianakis, 2004). 
In 2001, approximately 30\% of the entire Greek national student body studied abroad (Lianos et al., 2004). However, an exhaustive search of the literature failed to find a single study targeting acculturation, acculturative stress, or any of its associated effects within a Greek international student population. The majority of research on acculturation and Greek culture are focused on first- and second-generation Greek immigrants throughout different countries of the world (Koutrelakos, 2004; Laroche, Kim, \& Hui, 1997; Georgas, Berry, Shaw, Christakopoulou, \& Mylonas, 1996; Siefen, Kirkcaldy, \& Athanasou, 1996), not the sojourning student population.

\section{Present Study}

The present study attempts to investigate Greek international students' acculturation and acculturative stress experiences because of their general underrepresentation in extant acculturative literature, presenting the opportunity to take initial steps in collecting data on this understudied group. Consensual Qualitative Research (CQR) methodology was selected as it is an effective and successfully used method of examining qualitative data, utilizing systematic methodology and multiple researchers in data analysis to better understand complex data and reduce bias that can result with a single researcher (Hill et al., 2005). This study also attempts to replicate the methods of previous research (Constantine et al., 2005b) to help advance the existing qualitative research on international students. After a review of the existing literature on acculturation, acculturative stress, and cultural adjustment in international students, the following expectations/hypotheses regarding possible themes to emerge in this study include:

1. Positive and negative presojourn perceptions of the United States

2. Positive and negative postsojourn perceptions of the United States

3. Acculturative stress problems in the United States

4. Strategies for coping with acculturative stress problems

5. Peer and family networks

6. Prejudicial or discriminatory experiences in the United States

7. English language difficulties and usage

\section{RESEARCH METHOD}

\section{Participants}

Participants included eight Greek international students (men $=5$; female $=3$ ) attending a small, private predominantly white university in the Midwest who were attempting to complete requirements for either an undergraduate $(n=3)$ or graduate degree $(n=5)$. All of the participants, in accordance with inclusion criteria, identified as Greek. Ages ranged from 22 to 31 years of age $(M=25.63 \mathrm{SD}=3.02)$. All participants reported having sojourned to the United States between 6 and 36 months prior to participating in the study. All participants had lived in their home country 
prior to seeking an education in the United States and reported that their parents funded their educational expenses.

\section{Research Team and Bias Management}

In accordance with guidelines set by Hill et al. (2005), the research team for the present study included two male Caucasian-American doctoral candidates, two Greek international graduate students, and one Greek psychologist/graduate psychology professor. To increase the reliability and validity of data interpretations, all members of the research team received training on CQR procedures, goals, and methods. Two of the five researchers also had experience working with Greek international students. Their knowledge served to increase the research team's awareness of relevant themes found in the participants' descriptions of their acculturative experiences. The team also consensually discussed and documented its biases and expectations for the data before beginning the interpretive process in order to heighten awareness of such biases and promote objectivity throughout analysis.

\section{Procedure}

The university's Institutional Review Board approved the following study. The study followed all the necessary procedures to ensure confidentiality of participants. Prior to the interview process, participants meeting inclusion criteria completed and signed a written informed consent document. Demographic information was then gathered via a questionnaire before beginning the interview.

The two Caucasian male doctoral students conducted all semistructured interviews. Interviews utilized a series of pre-established, openended questions (see Appendix) as well as probing when necessary to elicit more detailed responses (Constantine et al., 2005b; Hill et al., 2005). All interviews were conducted in English, audio recorded, and lasted no more than 90 minutes. Participants were given contact information for a licensed psychologist as well as referrals to the university's counseling center if they felt they experienced any distress. All recordings were transcribed into text and checked for accuracy by a professional transcriptionist. When the transcriptionist completed her task, the co-investigator double-checked the text for accuracy. The accurate transcripts were distributed amongst the research team for initial coding into major domains, as outlined by CQR methodology (Hill et al., 2005).

\section{Qualitative Analysis}

CQR methodology, based in feminist and multicultural theory, places immense emphasis on a systemic methodology focused on respect for diverse viewpoints and on team consensus in data analysis as it provides the ability to eliminate power/privileged bias by giving all members an 
equal voice; results are not determined by just what the lead investigator concludes to be an ideal or bad category (Hill et al., 2005). Additionally, team members are able to discuss disagreements respectfully while coming to agreement on themes best capture the meaning of the data (Hill et al., 2005).

Table 1: Domains, Categories, and Subcategories from Cross-Analysis of Interviews with Greek International College Students

\begin{tabular}{|c|c|}
\hline Domain, category, and subcategory & Frequency \\
\hline $\begin{array}{l}\text { 1. Positive and Negative Presojourn Perceptions of the United States } \\
\text { a. The United States is a homogeneous country that is similar to other European } \\
\text { countries } \\
\text { b. The United States is similar to what is portrayed in popular culture, film, and music }\end{array}$ & General \\
\hline \multicolumn{2}{|l|}{ 2. Positive and Negative Postsojourn Perceptions of the United States } \\
\hline a. The United States is a geographically large country. & Variant \\
\hline $\begin{array}{l}\text { b. The United States is a more structured environment academically and } \\
\text { occupationally }\end{array}$ & Typical \\
\hline $\begin{array}{l}\text { c. The United States has more diffuse social rules and norms that allow for personal } \\
\text { expression. }\end{array}$ & Typical \\
\hline $\begin{array}{l}\text { d. The United States is a heterogeneous country with many different types of peoples, } \\
\text { cultures, and locations. }\end{array}$ & General \\
\hline \multicolumn{2}{|l|}{ 3. Acculturative Stress Problems in the United States } \\
\hline a. Isolation from family and friends. & General \\
\hline b. Financial concerns & Typical \\
\hline c. Becoming the minority & Variant \\
\hline d. Understanding and speaking English & General \\
\hline e. Daily living difficulties & General \\
\hline 1. Pace of daily living in United States (faster) & Typical \\
\hline 2. Difficulties obtaining and understanding basic living needs & Typical \\
\hline \multicolumn{2}{|l|}{ 4. Strategies for Coping with Acculturative Stress Problems } \\
\hline a. Obtain support from family members & General \\
\hline b. Obtain support from peers & General \\
\hline c. Cope with problems personally and without assistance & Typical \\
\hline d. Obtain support from faculty/mentors & Variant \\
\hline \multicolumn{2}{|l|}{ e. Open to seeking counseling } \\
\hline 1. Not open & Typical \\
\hline 2. Somewhat open & Variant \\
\hline \multicolumn{2}{|l|}{ 5. Peer and Family Networks } \\
\hline a. Positive family support network & General \\
\hline b. Positive peer based support network & General \\
\hline 1. Supportive network of Greek friends in the United States & Typical \\
\hline 2. Supportive network of American friends in the United States & Variant \\
\hline \multicolumn{2}{|l|}{ 6. English Language Usage and Difficulties } \\
\hline a. Limited vocabulary and grammar leading to difficulties with higher education & Typical \\
\hline b. Limited vocabulary and grammar leading to difficulties communicating with others & Variant \\
\hline \multicolumn{2}{|l|}{ 7. Cultural Concerns Regarding the U.S. or Native Country } \\
\hline a. Greece or Cyprus is a homogenous group of people & General \\
\hline b. The United States has a large variety of peoples, religions, and traditions & General \\
\hline c. The United States work culture is fast paced and demanding & Typical \\
\hline d. Greece is not as accepting of differing traditions and/or cultures & Variant \\
\hline
\end{tabular}

With this in mind, the first step in analysis was to formulate domains. In line with the methodology proposed by Hill et al. (2005), domains were initially created utilizing a 'starter list' based on extant literature, specifically Constantine et al.'s (2005b) study. This list is found in the hypotheses/expectations listed under the 'Present Study' section. Using this 'starter list,' each research team member independently reviewed the transcripts without communication with other team members. Members coded blocks of data (phrases, sentences) into the domains they deemed 
appropriate. Upon individual completion, all members rejoined and discussed their codings. Through discussion and consensual agreement amongst all members, an edited list of seven domains was created that accurately captured all data.

Two research team members then independently constructed core ideas (brief summaries) of the data provided by the participants in their interviews. These researchers then discussed their created core ideas with one another and reached agreement on a final list of abstracted core ideas. Next, through cross-analysis of core ideas, the researchers constructed categories based upon similarities in participants' core ideas contributing to each domain. Thus categories were an extension of their respective domains. Subcategories were derived from categories when differing responses were given by two or more participants in order to represent alternative and unique experiences within a categorical area (Hill et al., 2005). Following CQR methodology, all categories and subcategories received one of three classifications. A category or subcategory discussed in all cases received the highest classification, general $(n=8)$; a category or subcategory identified in half or more of the cases $(n=4-7)$ was classified as typical; and a category or subcategory applied to two or three cases was classified as variant. Any category or subcategory assigned to only one case was dropped because it is not considered descriptive of the overall sample (Hill et al., 2005). See Table 1 for the finalized list of domains and categories and subcategories and their frequency.

\section{RESULTS}

\section{Domain 1: Positive and Negative Presojourn Perceptions of the United States}

Participants generally stated they had few specific expectations regarding the United States prior to studying in the country. However, all participants did expect it to be different from their home country. From this general expectation, two subcategories developed. The first general subcategory involved expectations based upon media portrayals (television, music, movies) of popular culture. For example, a female participant stated

I kind of had an idealized picture of the U.S. in my mind, because I would like - watched hundreds of movies before I came. So it's like this is a perfect place, like where people fall in love...

Other participants echoed this sentiment. The second general subcategory involved an expectation that despite differences from participants' home country, the United States would be similar to other European countries (excluding language differences). This expectation was based on participants' past visits to relatives and friends living in other European 
countries. One male student stated, "I did not have expectations. If you go to Europe, it's the same thing as being in your [native] country. But if you come here it's so different. Everything is different.” Another participant indicated that her limited specific expectations and naiveté regarding the United States was in part due to popular culture influences of the United States, as her exposure to other European countries and cultures had led her to believe these places were very homogenous in ethnicity, religion, people, ideas, etc. concluding that, "Why would the U.S. be any different then? But it was.”

\section{Domain 2: Positive and Negative Postsojourn Perceptions of the United States}

All participants indicated that after coming to the United States to pursue higher education, they recognized the diverse nature of the country. They stated their initial perceptions of it being similar to Europe or to popular culture portrayals were largely mistaken. Those who described their postsojourn perceptions in greater detail often noted how there are various types of people, religions, cultures, customs, and regional differences in the United States. The diversity of the country took participants by surprise, eliciting culture shock in some. Some described how their European experiences had been very homogenous and very similar to Greece or Cyprus (Greek island). One participant noted how American movies highlight a general view of the United States that is incongruent with the environment in which they are studying (Midwestern medium-sized city). A female student commented that although there are ethnic minorities in movies, she didn't think they exposed people to how heterogeneous the United States really is nor did she think people from Cyprus really contemplate the diversity portrayed in some movies.

A typical category that developed from the postsojourn perceptions of the United States was the flexibility of social rules regarding dress, behavior, and social interactions. Those who reported these observations consistently compared them to their native country's social rules and norms. Half of the students stated that in a smaller country like Greece, and especially Cyprus, the general population is concentrated on an individual's appearance. These students indicated many people talk negatively of others based on their physical appearance or dress. This was a stark contrast to participants' experience in the United States where they witnessed such an occurrence happening to a lesser degree. People here did not seem to care about what others were doing or wearing. One student stated he found this decrease in negative talk and loose social norms regarding appearance to be good as worrying about peoples' perceptions of oneself is restrictive.

These same participants indicated the culture of the United States was far more structured and focused on punctuality and work ethic than the culture of Greece or Cyprus. One individual who endorsed the more 
relaxed social acceptance but structured nature of time in the United States stated,

You have a schedule every day, like you have to do 8:00 to 10:00 this, 10:00 to 2:00 that. And when you have free time, it's not your free time, it's actually like it's something to do like has homework or something, so it's never actually free time.

Another participant commented on the punctuality of classes, being unaccustomed to the expectation of arriving to class exactly on time. These two seemingly opposite categories speak to the "open-mindedness" of higher education as well as the goal-driven and productivity-focused nature of the American culture.

One variant category that emerged was the concept of the immense geographic nature of the United States. When asked their initial impression of the United States upon arriving, some students responded to the large physical size of the country versus notable differences in population, culture or social norms.

\section{Domain 3: Acculturative Stress Problems in the United States}

A number of respondents indicated more than one source of acculturative stress in their adjustment to student life in the United States. All participants frequently mentioned their physical isolation from family and friends as a general, ongoing source of acculturative stress. One female student stated, “...I miss my whole family." She explained her close familial ties to various family members, including both her immediate and extended family, making her travel here "harder" and the isolation as one of the main reasons she did not want to move to the United States permanently.

Participants generally perceived a variety of daily living tasks as difficult. From this category two typical subcategories surfaced highlighting two specific daily living tasks. The first concerned a lack of understanding of and obtaining the basic living needs for living in the United States as family members usually provided for such needs. The second subcategory involved the pace of living in the United States and the participants' difficulty adapting their daily needs to this schedule. For example, one male student pointed out when discussing turning in assignments and paying bills on his own,

Here you have no --you know, you have no time. You have to bring, you know, your payment tomorrow? You must do it today. I mean you cannot say, "I...will do it tomorrow," it has to be done now. 
Another female student commented on how Americans are so focused on work with no time for other things, calling them "workaholics." Another general category within this domain was understanding and speaking English. While participants' responses varied in their level of understanding and speaking English, they all stated it caused a large amount of stress and adjustment problems in almost every area of their lives. One student commented on how during her first year no one could understand her and that she did not know how to speak English except for a few simple words. In her words, "it was difficult to meet people not from Greece and to do my work when no one could understand me. I mean, in my ears I could understand, but for them it was some different language." Then in her second year here and through her involvement on the swim team, she learned more English and was able to speak more clearly.

Financial issues were also a typically noted stressor, causing distress and acting as an inhibitor in participants' ability to adapt to life in the states. For example, a female student talked about her financial concerns stating she could not make it here on her own due to an inability to make money and having to work illegally. Another student commented on the financial stress of high tuition costs as a stressful part of his acculturation process, stating, “... And I have to pay double what the others are paying because I'm not a resident of the United -- of Indiana. So that a big problem I had as an international student...the money.”

Suddenly becoming a minority when the individual had been a part of the majority class for most of his or her life emerged as a variant category for sources of acculturative stress. One student stated,

Like I mean in Cyprus we don't even have like -- we have a minority, but it's completely separate with us because of war in '74, so basically the south side of the island, where in the majority, we're like all Greek Cypriots. And then maybe you have like 2 percent of Europeans living around. So when I come here and I see like there's so much difference, like Asians, Latinos, like - the Europeans just mingle all together...Which, for me is being an outsider, I see it like that.

\section{Domain 4: Strategies for Coping with Acculturative Stress Problems}

All participants reported seeking out familial and peer resources when they needed assistance in coping with adjusting to the culture of the United States or for various types of experienced stress. One male participant reported, "I have a friend here and I will go first to her, or I will call my parents in Cyprus.” A typical response, in addition to dealing with problems by using familial and peer support, was to solve problems independently without any specific assistance. Using professors or 
mentors/advisors for support for problems or stress also emerged as a variant category.

Participants typically reported that they were not open to considering counseling as a coping method for dealing with acculturative stress or adjustment issues. One male student stated, "I am never going to do that." Others shared his opinion and another student gave her rationale for rejecting counseling by stating,

That's very interesting, because I was talking with a friend of mine, I won't say the name, but he's studying psychology here, so we were talking about [this] during coffee and it's like this is why Greek and Cypriots don't need psychology. It's because they have their friends and they go for coffee three hours a day and they talk about their problems. So for me like I hear people saying, I went to the counselor and I was stressed out and all that, and I cannot understand that problems and have stresses and [that] you need to talk to someone, because our life basically revolves around talking to other people, you know to old friends.

Participants who were open to seeking counseling were only somewhat open to the idea and if the problem was very serious (variant).

\section{Domain 5: Peer and Family Networks}

Participants generally reported they had strong, positive, and available family and peer support to help them cope with their acculturative stress and adjustment issues during their time in the United States. As one female participant indicated, "My family is always available if I need them." Another participant noted, "Our friends are like our family here..."

Two compelling subcategories arose within this domain. One variant subcategory endorsed by participants was having a strong support network of American friends, with a female student commenting on how an effort should be made to get to know Americans and become involved in the culture of the country. The second, typical subcategory was the concept of having a strong support network of Greek friends in the United States.

\section{Domain 6: English Language Usage and Difficulties}

This domain specifically addresses the use of the English language and its interference with daily life as all participants endorsed it as a stressor. When examined closely, two categories emerged. The first typical category dealt with the difficulties of speaking and using English in a higher education setting. Results indicated that most of the participants reported difficulties in formal learning environments. For example, a male participant commented on his initial language difficulties saying, "Because I was trying to be in class, and people talking it was hard to do [the work]. 
And I was not having any people from my country to speak with.” He also stated that through his classes and readings he was able to better understand the language and improve his English. He now participates in conversations in his classes and his grades have improved compared to his initial struggles with the English language.

Those who reported educational issues due to language problems also reported that staff and faculty assisted them until they were more proficient. However, one participant commented that he felt there was a lack of advanced English language education for many of his Greek peers. The second variant subcategory dealt with difficulties using English to engage with others in a social or professional manner outside the classroom. One of the two participants reporting such difficulties stated, “And language -- it was, because first was difficult, because I like to be talking and make friends to people, you know? And I'm agitated, and I want to talk. And I felt that I couldn't express myself."

\section{Domain 7: Cultural Concerns Regarding the United States or Native Country}

This domain was divided into four categories. Many of these categories are similar to those discussed in the postsojourn perceptions domain. The research team consensually agreed however they are also opinions and evaluations of cultural differences between participants' native country and the United States. One category expressed by all participants was the large, diverse nature of the United State's peoples, religions, and traditions compared to participants' native country. One female participant stated, "And it was kind of like I realized how homogenous Cyprus is and how different people grow up here...” Another general category involved how Greece is predominantly one sole Greek culture with very limited native diversity. A participant commented on how a majority of the area is solely Greek Cypriots with minorities completely separated from them. Related to this, a variant category addressed how there is some Greek/Cypriot intolerance for diversity. The following female student best conveys this concept,

And it's different for us [Cypriots], especially a foreign -- a foreigner would never survive in Cyprus unless -- no, no, actually. No, not that easily, unless you know somebody who already has friends and is going initiate you, let's say, to a bunch of people so you can go out. Because we don't really have any culture other than Cypriot or Greek there. I mean, the other races that we have is Pakistan, and Filipino, and all these people are considered inferior because they also -- they all of them work as maids or do something -- like the Mexicans, I would say. So that's the only foreign people we have. And we're not open to any other culture... 
The difference in work pace in the United States versus participants' native country also emerged as a typical category.

\section{DISCUSSION}

While the present study's findings contribute to the extant literature on acculturation, adjustment, and acculturative stress, they are not sufficient to make broad statements predicting how Greek international students will experience or cope with stress. However, when compared to previous literature examining the same issues with international students, there appear to be similar findings shared between the literature and the present study (Constantine et al., 2005b, Constantine et al., 2005c, Koutrelakos, 2004; Rajapaksa \& Dundes, 2003). Some of these shared major findings include language proficiency, social acceptance, and overall time spent in the United States as sources of distress.

Previous research has repeatedly tried to identify global themes representative of all races, ethnic groups, and nationalities. The unique contribution of the present study is its focus on a specific nationalitycultural group rarely studied in the acculturative literature, Greek international students, and its identification of themes regarding how that group acculturates to life at a small, private college in the United States. Secondary goals of the present study were to replicate methods used in previous research (Constantine et al., 2005b) and to assist in advancing the existing qualitative research on acculturation of specific populations. The study revealed several areas affecting this sample of Greek international students' acculturation processes including pre- and postsojourn expectations and perceptions, English language proficiency, the ability to function independently with daily living tasks, isolation from family, strategies for coping with acculturation, and peer and family networks.

\section{Pre- and Postsojurn Expectations}

Participants' presojurn expectations of the country included that the United States was a country very similar to other nearby European nations. These geographically close nations are considered part of the "western civilized world," and therefore might have many similarities with the United States. Participants also firmly believed media portrayals of the United States to be congruent with the reality of American life. However, most of the postsojourn perceptions focused on the diverse nature of the United States. Emphasis was placed on differences in social norms, academic achievement, occupational goals, and time management. Many participants had an idealistic "Hollywood" view of the United States. These perceptions about the United States included beliefs about wealth, 
access to entertainment, and the lifestyle, opinions, and beliefs of Americans. This led many to have a strong reaction to the reality of the United States, Indiana, and more specifically, the small private university where participants were going to study. One individual described her reaction as a complete "culture shock" with her beliefs about the United States being completely wrong. She was unprepared to deal with these substantial discrepancies.

While other participants did not report experiencing culture shock, many experienced significant distress and disappointment from the discrepancies between their expectations and the reality of the United States. Many appeared resentful and disappointed by the structured academic and occupational culture of the United States. Others were overwhelmed with the enormous physical size of the United States. This is important as extant literature has identified that a student's presojourn perceptions about a host country may lead to acculturative stress, depression, disappointment, culture shock, anger, and resentment when their perceptions and assumptions are proven false by postsojourn observations (Mori, 2000).

\section{Identified Acculturative Stress \& Coping Strategies}

One common area of acculturative stress often discussed in the extant literature is experiences of prejudice and discrimination against international students (Altbach, 2004a; Altbach, 2004b; Constantine et al., 2004; Constantine, Alleyne, Caldwell, McRae, \& Suzuki, 2005a; Constantine et al., 2005c; Farver, Narang, \& Bhadha, 2002). However, none of the participants discussed such experiences. This does not mean the participants were never discriminated against during their time in the United States. It does indicate though that if they did experience any discrimination or prejudice, it did not increase their acculturative stress or affect their ability to adjust to life in the United States. The university may have assisted in shielding the students from discrimination, possibly due to departments like the International Division and their cultural education programs.

Additionally, while the university may engage in activities encouraging others to celebrate differences, these students may also experience little or no discrimination because of the color of their skin (Hunter, 2007; Uhlmann, Dasgupta, Elgueta, Greenwald, \& Swanson, 2002). Since Greeks are considered to be Caucasians, they may experience less exposure to these stressors that other international student groups endure. Skin tone and its relationship to discrimination and prejudice has been well documented in sociological texts (Hunter, 2007). These texts indicate that individuals who are light-skinned are generally more accepted and experience less discrimination than individuals who are dark-skinned. 


\section{English Language Difficulties}

Previous literature has extensively documented international students' difficulty with their host countries' language and its impact on acculturation and acculturative stress (Mori, 2000; Pedersen, 1991). Though participants' linguistic abilities and its association with the degree of stress experienced by each individual varied, all participants reported language difficulty as a source of stress regardless of ability. Literature states that the more significant the language barrier or deficit, the more profound an impact the stress has on an individual's ability to acculturate and function well psychologically (Constantine et al., 2004; Farver, Narang, \& Bhadha, 2002; Mori, 2000; Ghuman, 1997; Sodowsky \& Plake, 1992; Pedersen, 1991). This study could not quantify participants' amount of distress or language ability, but results do indicate that the time spent discussing the topic increased as the participant's reported English language ability decreased. For example, a participant who reported an inability to speak fluent English also discussed the importance of his language difficulty and his associated stress throughout the entire interview.

\section{Familial Isolation}

All participants reported undergoing stress due to being physically isolated from their families. Many spoke of how they missed their parents for emotional and financial support. Additionally, and as cited in the literature (Thomas \& Althen, 1989), most participants reported having mostly Greek friends. Thomas and Althen's (1989) study highlighted that while international students maintain their affiliation to others of identical nationality, ethnic minorities rely on familial supports and geographically close peers. Students in this study who reported significantly missing many aspects of family life (food, holidays, physical connection, financial support) more often reported forming relationships with other Greeks or international students as opposed to with Americans. This is supported in other extant literature, as international students are more likely to be friends with other international students, with approximately $40 \%$ of this population having no American friends (Rajapaksa \& Dundes, 2003). However, individuals in this study who reported being mildly distressed by the distance from their families were better able to make friends and support networks involving any race, ethnicity, or nationality.

Participants who quickly found a supportive group of friends often found their ability to adapt and adjust to life in the United States increased. Participants who formed tight knit groups of Greeks/Cypriots and utilized peers as a major coping strategy for acculturative stress often referred to these groups as "family" in their narratives. These findings highlight the necessity of maintaining social relationships with individuals who can validate the student's sense of self and ways of being (Constantine et al., 2005b). 


\section{Peer and Familial Support Networks}

All participants reported having overall positive familial and peer support networks, regardless of distance. Participants discussed their ability to connect or reconnect with new and old friends, both near and far, to help build a strong support network for themselves. This is a cultural component of Greek life, a coping mechanism, and a preventative measure against future stressors. Within the extant literature on international student acculturation, many researchers propose that forming these connections with others are vital and could reflect the strong cultural values of collectivistic societies and groups (Koutrelakos, 2004; Georgas et al., 1996; Sandhu \& Asrabadi, 1994). The majority of the participants also reported having daily conversations with their family. These strong familial ties are supported in much of the literature surrounding sojourning immigrants and students to the United States (Berry, 2001; Phinney, Horenczyk, Liebkind, \& Vedder, 2001).

Greek international students struggling with the English language and the distance from their families tend to desire close "familial" peer groups. This coping mechanism serves two purposes: increasing their exposure to their native language and creating bonds similar to those with their families in their native country (Koutrelakos, 2004; Berry, 2001; Phinney et al., 2001). This is just one example of Greek international students' approach to coping with adjustment, acculturation stressors, and even psychological concerns.

\section{Daily Independent Living Stressors}

All participants discussed their initial difficulties with daily living tasks such as obtaining housing, establishing financial means and storage, obtaining utility services, obtaining proper documentation, and paying bills. Learning and engaging in these activities for the first time was very stressful for many participants. Those who reported issues often relied on the assistance of others as a coping method. For one individual it was a significant enough stressor that she contemplated leaving the university; she was unfamiliar with any of the tasks required for independent living in the absence of direct parental or familial influence.

Other participants explained that although their lack of knowledge of these required tasks was initially difficult, they eventually were able to implement coping strategies to decrease the severity of their stress. Such reports highlight how the intensity and frequency of discussion of this stressor as well as its effects on one's ability to adapt varied with each participant. This study's results also support previous research that found international students who lived off campus and were supported by their parents (not operationally defined) were more likely to experience more signs of acculturative stress and feelings of depression (Rajapaksa \& 
Dundes, 2003). While this does not implicate difficulties in independent living as the source of acculturative stress, they may be an important contributing factor.

\section{Independent Coping Strategies}

Many participants indicated a preference to address their difficulties with adjustment and their acculturative stress directly. Studies have shown that Greeks and Greek-Americans score lower on measures of selfdisclosure and withdrawal from relationships to protect and maintain autonomy while sustaining a strong sense of self-reliance (Koutrelakos, 2004). Other research indicates that while Greeks may be protective of their autonomy, the egalitarian relationships they develop with others tend to be characterized by open communication (Kagitcibasi, 1985). This concept of withdrawal and self-reliance further supports that Greeks favor the collectivistic value of placing the needs of the group over the needs of the self. If one withdrawals and attempts to solve their problems independently, they are not taxing the group. After unsuccessful attempts, an individual may seek out assistance from those whom they views as equals. Using an individual of perceived authority would only utilize resources that were not deemed necessary by the group (Koutrelakos, 2004).

This flow between self-reliance, utilization of familial support, and group assistance explains the variety of responses given by the participants, with individuals frequently endorsing more than one coping strategy. For example, one individual indicated he would first attempt to independently solve his problems, then he would seek out familial assistance, and then, only if that was not helpful and he was in dire need, would he seek professional assistance. As a society we often admire and encourage selfreliance, however not disclosing one's distress could potentially lead to a decrease in academic performance, socialization, or occupational function.

\section{Utilizing Mentors and/or Faculty}

While researchers have examined the acculturative process of Greeks (Koutrlakos, 2004; Orfanos, 2002; Kagitcibasi, 1999; Triandis, 1990), most investigations deal with familial and professional support and its stigma amongst Greeks. However, the role of the professor or university mentor/staff member as a resource for Greek international students has not been extensively explored. Results of this study indicate that although they are rarely utilized, professors and mentors are considered a viable and socially acceptable resource in lieu of professional help. In fact, seeking faculty or staff support was frequently considered one of the earlier potential steps to take to adjust to acculturative stress versus seeking professional help. Many students believed it was a more comfortable 
option. Participants also indicated a variety of professors, regardless of their national origin, whom they believed would be helpful.

Through education and information given by student support services, universities could encourage Greek international students to utilize trusted faculty members as a support network if they feel they are having difficulties adapting to the United States. Additionally, with the aid of professors/mentors, students could view the counseling center as less stigmatizing, increasing their likelihood to utilize services before a situation turns from stress to crisis.

\section{Seeking Counseling Services}

Most participants were quick to indicate they were not open to seeking out professional counseling or psychological services to discuss their acculturative stress or adjustment issues. Underutilization of psychological services for acculturation problems among international students and immigrants has been investigated thoroughly (Constantine et al., 2004; Koutrelakos, 2004; Mori, 2000; Niles 1999; Harris \& Vernon, 1998; Pedersen, 1991). The literature surrounding the underutilization of mental health services has developed numerous reasons for not seeking assistance. Most of them are culture specific and deal with cultural values and belief systems; this was also the case in the present study. A previous study involving Greek students, specifically Greek-American students, discussed the impact of acculturation on the individual's attitude toward mental health services. The higher the assessed level of acculturation (across genders) the more open the participants were to seeking counseling (Ponterotto et al., 2001). While not specifically examined in the present study, participants who reported being somewhat open to counseling were those who had been living in the United States for a longer amount of time (more acculturated). However, there were other individuals who have had been living in the country almost as long and were adamantly opposed to counseling and psychotherapy as a support service.

\section{IMPLICATIONS}

The following implications are practical extensions of the study's results and could be evaluated using an expanded form of its methodology in future research. There appear to be two main areas for these implications: for the students and for the support staff and professionals working with them.

The drastic contrast between students' pre- and postsojurn perceptions of the United States and the university could be addressed prior to their travel to the country. Educational seminars discussing the life, culture, beliefs, and diversity of the United States and the state where the university is located as well as norms of academia and university life could be offered, 
possibly reducing the impact of the large cultural transition Greek international students experience prior to their sojourn and assisting in modulating the distorted expectations of students. Seminars could also provide information on how to obtain necessary basic needs to live independently in the United States as well as normalize the adjustment period many students experience. Pre- and postsojurn language workshops could be provided to students struggling with English. A quick and intensive basic English course could be offered prior to a student's trip. If the student continues to struggle, offering them the chance to be involved with some of the immersive English as a Second Language (ESL) classes housed on many college campuses may also be helpful. Existing programs such as tutoring and mentee positions could also be provided to Greek international students. These proposed interventions could serve as preventative measures for decreasing discrepancies and associated acculturative stress levels.

Members of the teaching community such as staff, medical providers, mental health care workers, and professors could be better informed via educational training opportunities about the relationships, roles, and inherent norms that may be involved when working with Greek international students and the unique cultural component that each Greek student encompasses. Counselors and psychologists could aid in combating acculturative stress by hosting outreach/psychoeducational programs and guest lecturers to better educate Greek and Cypriot international students about when adjustment and acculturative distress levels become so high that professional mental health interventions may be both necessary and beneficial. These professionals should also be aware of the possible embedded cultural beliefs and stigma towards professional help, utilizing caution before labeling a student's behavior as resistant. Additionally, in order to attempt to decrease stigma toward mental health, professionals may need to adapt their role to include characteristics of the Greek international students' culture, traditions, and socio-norms to build trust in the therapeutic alliance. Mental health professionals should also be able to identify and implement culturally acceptable treatment interventions. This could include encouraging students to utilize the support systems they are accustomed to.

Based on the rich narratives that developed from interviewing only a few Greek international students, the university, with the assistance of counselors, could implement a similar interviewing process with a select number of new international students each year. The protocol can be altered to be proactive about potential acculturative stressors and adjustment difficulties that certain ethnic or nationality groups may have in transitioning to university life. This open dialogue can also be offered to international students whom have been studying at the university for 
numerous semesters to help develop additional programs and services to better meet their changing needs.

Further research is needed to validate these hypotheses as well as explore other possible implications. However, any supplemental education and knowledge imparted to both university staff/faculty and students can only facilitate further discussion and open communication. This open dialogue can lead to program implementation and continued research on the vast and complex ways that Greek international students may experience and adapt to their acculturative stress.

\section{LIMITATIONS AND FUTURE RESEARCH}

This study was extensive, properly performed, and analyzed; however, it is not without limitations. The present study's sample size was small $(\mathrm{n}=8)$ and less than those of other CQR studies (Constantine et al., 2005b; Ladany et al., 1997; Rhodes et al., 1994). With a larger sample size, this study may have found additional results congruent with extant literature. Despite the present study's small sample size, it was still within methodological requirements of CQR ( $\mathrm{n}=8-15$; Hill et al., 2005) and does not affect the validity of data gathered. This study also focused on a small sample of a specific population at a small Midwestern university. Though results of this study are consistent with other research regarding Greeks and international students, caution should be utilized in making any broad generalizations from it. International students at other universities in different locations of the United States may have different experiences compared to this study's sample.

Finally, the present study is based on the interpretations of a team of researchers. Although safeguards were implemented to account for and limit the influence of potential biases, some inherent biases always exist and thus may have affected the study at any level of research. One example of bias is the lack of participant involvement in data analysis to ensure accurate interpretations. While not a requirement of CQR methodology, it is commonplace in most qualitative research. Many of the participants had terminated their studies at this institution or finished their degree requirements and returned to their native country by the time of data analysis. Due to these considerations, researchers should attempt to replicate this study, including participant feedback into the process. Another potential bias is the research team's lack of use of the auditing step of CQR. Due to geographical and availability constraints, the research team was unable to procure someone outside the team to audit coded transcripts and developed categories. Rather than eliminate this step, a member of the research team also served as an auditor, possibly limiting the domains, categories and subcategories developed. 
This study provides a foundation for future research seeking to investigate many of the phenomena experienced by Greek international students in the study. Utilizing the present study's methodology, future research should extend to universities located in other areas of the United States. It is reasonable to hypothesize that in a different environment, such as in a large metropolitan city, different acculturative stress and adjustment issues may exist. Through results comparisons amongst various studies, researchers could begin to draw more general claims about the most important factors affecting Greek international students' ability to acculturate as well as how these students tend to adapt and cope.

Another area for further exploration is the stress experienced because of significant discrepancies between pre- and postsojurn perceptions. Further qualitative and quantitative research investigating this large discrepancy could provide vital information for international student support staff and counselors at both the host and native university. Examining what types of factors surrounding a problem for Greek international students warrants seeking psychological or counseling services is also of importance. Related to this, qualitative research projects could examine the experiences of when Greek or other international student populations seek out health and wellness services as well as the experiences of Greek students who sought out counseling and those who did not. Studies could also compare the verbalized rationales for seeking primary medical care over seeking mental health services.

Finally, according to Clara Lovett (2008), the higher education system needs to shift its focus from simply "knowing each other" to "help[ing] students see the world and its wonders and problems through the eyes and minds of others, to explore alternative interpretations of events and trends" (pp. A40). To achieve this goal, researchers and educators must collaborate to help meet the needs of the students sojourning to the United States and encourage them (and our native students abroad) to push their personal boundaries and truly experience and adapt to our cross-cultural world.

\section{REFERENCES}

Abe, J., Talbot, D. M., \& Geelhoed, R. J. (1998). Effects of peer program on international student adjustment. Journal of College Student Development, 39, 539-547.

Altbach, P. G. (2004a). Higher education crosses borders. Change, 36(2), 18-25.

Altbach, P. G. (2004b). Globalization and the university: Myths and realities in an unequal world. Tertiary Education and Management, 10(1), 3-25.

Berry, J. W. (1980). Acculturation as varieties of adaptation. In A. M. Padilla (Ed.), Acculturation: Theory, model and some new findings. Boulder, CO: Westview.

Berry, J. W. (2000). Marginalization. In A. E. Kazdin (Ed.), Encyclopedia of psychology (vol. 5, pp. 105-108). Washington, D.C.: American Psychological Association.

Berry, J. W. (2001). A psychology of immigration. Journal of Social Issues, 57(3), 615-631.

Berry, J. W. (2003). Conceptual approaches to acculturation. In K. M. Chun, P. Balls 
Organista \& G. Marín (Eds.), Acculturation: Advances in theory, measurement, and applied research. (pp. 17-37). Washington, D.C.: American Psychological Association.

Berry, J. W. (2006). Acculturative stress. In P. T. P. Wong \& L. C. J. Wong (Eds.), Handbook of multicultural perspectives on stress and coping (pp. 287-298). Dallas, TX: Springer Publications.

Berry, J. W., \& Kim, U. (1988). Acculturation and mental health. In P. R. Dasen, J. W. Berry \& N. Sartorius (Eds.), Health and cross-cultural psychology: Toward applications (pp.207-236). London: Sage.

Berry, J. W., Kim, U., Minde, T., \& Mok, D. (1987). Comparative studies of acculturative stress. International Migration Review, 21(3), 491-511.

Constantine, M. G., Okazaki, S., \& Utsey, S. O. (2004). Self-Concealment, social selfefficacy, acculturative stress, and depression in African, Asian, and Latin American international college students. American Journal of Orthopsychiatry, 74(3), 230-241.

Constantine, M. G., Alleyne, V. L., Caldwell, L. D., McRae, M. B., \& Suzuki, L. A. (2005a). Coping responses of Asian, Black, and Latino/Latina New York City residents following the September 11, 2001 terrorist attacks against the United States. Cultural Diversity \& Ethnic Minority Psychology, 11(4), 293-308.

Constantine, M. G., Anderson, G. M., Berkel, L. A., Caldwell, L. D., \& Utsey, S. O. (2005b). Examining the cultural adjustment experiences of African international college students: A qualitative analysis. Journal of Counseling Psychology, 52(1), 57-66.

Constantine, M. G., Kindaichi, M., Okazaki, S., Gainor, K. A., \& Baden, A. L. (2005c). A qualitative investigation of the cultural adjustment experiences of Asian international college women. Cultural Diversity \& Ethnic Minority Psychology, 11(2), 162-175.

Farver, J. A. M., Narang, S. K., \& Bhadha, B. R. (2002). East meets west: Ethnic identity, acculturation, and conflict in Asian Indian families. Journal of Family Psychology, 16(3), 338-350.

Furnham, A. \& Bochner, S. (1982). Social difficulty in a foreign culture: an empirical analysis of culture shock. In S. Bochner (Ed.), Cultures in contact: Studies in cross-cultural interaction (pp.161-198). Oxford: Pergamon Press.

Georgas, J., Berry, J. W., Shaw, A. C., Christakopoulou, S., \& Mylonas, K. (1996). Acculturation of Greek family values. Journal of Cross-Cultural Psychology, 27, 329-338.

Ghosh, S., \& Lu, W. (2003). Transnationalism and identity: A tale of two faces and multiple lives. Canadian Geographer, 47(3), 269-282.

Ghuman, P. A. S. (1997). Assimilation or integration? A study of Asian adolescents. Educational Research, 39(1), 23-35.

Harris, A. C., \& Vernon, R. (1998). Acculturation as a determinant of Greek-American family values. Psychological Reports, 83(3), 1163-1172.

Hayes, R. L., \& Lin, H. (1994). Coming to America: Developing social support systems for international students. Journal of Multicultural Counseling and Development, 22, 7-16.

Hill, C. E., Thompson, Knox, S., B. J., Thompson, B., Williams, E. N., Hess, S. (2005). Consensual qualitative research: An update. Journal of Counseling Psychology, 52(2), 196-205.

Hunter, M. (2007). The persistent problem of colorism: Skin tone, status, and inequality. Social and Personality Psychology Compass, 2(1), 237-254.

Institute for International Education. (2014). Open doors: Welcome. Retrieved from http://opendoors.iienetwork.org/

Kagitcibasi, C. (1985). A model of family change through development: The Turkish family 
in comparative perspective. In I. R. Lagunes \& Y. H. Poortinga (Eds.), From a different perspective: Studies in behavior across cultures (pp. 120-135). Lisse, Netherlands: Swets \& Zeitlinger.

Kagitcibasi, C. (1999). The model of family change: A rejoinder. International Journal of Psychology, 34, 15-17.

Koutrelakos, J. (2004). Acculturation of Greek Americans: Change and continuity in cognitive schemas guiding intimate relationships. International Journal of Psychology, 39(2), 95-105.

Kurman, J., Eshel, Y., \& Zehavi, N. (2005). Personal and group acculturation attitudes and adjustment: Russian and Ethiopian immigrants in Israel. Journal of Applied Social Psychology, 35(5), 956-974.

Ladany, N., O'Brien, K., Hill, C. E., Melincoff, D. S., Knox, S., \& Petersen, D. (1997). Sexual attraction toward clients, use of supervision, and prior training: A qualitative study of psychology predoctoral interns. Journal of Counseling Psychology, 44, 413-424.

Laroche, M., Kim, C., \& Hui, M. K. (1997). A comparative investigation of dimensional structures of acculturation for Italian Canadians and Greek Canadians. Journal of Social Psychology, 137(3), 317-331.

Lianos, T. P., Asteriou, D., \& Agiomirgianakis, G. M. (2004). Foreign university graduates in the Greek labour market: Employment, salaries and overeducation. International Journal of Finance and Economics, 9, 151-164.

Lovett, C. (2008). We need a new model of global education. The Chronicle of Higher Education: Commentary, 54(31), A40.

Mori, S. (2000). Addressing the mental health concerns of international students. Journal of Counseling \& Development, 78(2), 137-144.

Niles, F. S. (1999). Stress, coping and mental health among immigrants to Australia. In W. J. Lonner, D. L. Dinnel, D. K. Forgays \& S. A. Hayes (Eds.), Merging past, present, and future in cross-cultural psychology: Selected papers from the Fourteenth International Congress of the International Association for CrossCultural Psychology. (pp. 293-307): Swets \& Zeitlinger Publishers.

Olaniran, B. A. (1993). International students' network patterns and cultural stress: What really counts. Communication Research Reports, 10, 69-83

Orfanos, S. D. (2002). The Greek American dance of continuity and integration. In S. D. Orfanos (Ed.), Reading Greek America (pp. 361-379). New York: Pella.

Pedersen, P. B. (1991). Counseling international students. Counseling Psychologist, 19(1), 10-58.

Pedersen, P. B. (1997). Culture-centered counseling interventions: Striving for accuracy. Thousand Oaks, CA: Sage.

Phinney, J. S., Horenczyk, G., Liebkind, K., Vedder, P. (2001). Ethnic identity, immigration, and wellbeing: An international perspective. Journal of Social Sciences, 57(3), 493-510.

Ponterotto, J. G., Rao, V., Zweig, J., Rieger, B. P., Schaefer, K., Michelakou, S., et al. (2001). The relationship of acculturation and gender to attitudes toward counseling in Italian and Greek American college students. Cultural Diversity and Ethnic Minority Psychology, 7(4), 362-375.

Poyrazli, S., Kavanaugh, P. R., Baker, A., \& Al-Timimi, N. (2004). Social support and demographic correlates of acculturative stress in international students. Journal of College Counseling, 7(1), 73-82.

Rajapaksa, S., Dundes, L. (2003). It's a long way home: International student adjustment to living in the United States. Journal of College Student Retention: Research, Theory and Practice, 4(1), 15-28.

Rhodes, R. H., Hill, C. E., Thompson, B. J., \& Elliott, R. (1994). Client retrospective recall of resolved and unresolved misunderstanding events. Journal of Counseling Psychology, 41, 473-483. 
Sandhu, D. S., \& Asrabadi, B. R. (1994). Development of an acculturative stress scale for international students: Preliminary findings. Psychological Reports, 75, 435-448.

Siefen, G., Kirkcaldy, B. D., \& Athanasou, J. A. (1996). Parental attitudes: A study of German, Greek, and second generation Greek migrant adolescents. Human Relations, 49(6), 837-851.

Sodowsky, G. R., \& Plake, B. S. (1992). A study of acculturation differences among international people and suggestions for sensitivity to within-group differences. Journal of College Student Development, 33, 53-59.

Sykes, I. J., \& Eden, D. (1985). Transitional stress, social support, and psychological strain. Journal of Occupational Behavior, 6, 293-298.

Thomas, K., \& Althen, G. (1989). Counseling foreign students. In P. B. Pedersen, J. G. Draguns, W. J. Lonner \& J. E. Trimble (Eds.), Counseling across cultures (3rd ed.). (pp. 205-241): University of Hawaii Press.

Triandis, H. C. (1990). Cross-cultural studies of individualism and collectivism. In J. J. Berman (Ed.), Cross-cultural perspectives: Nebraska Symposium on Motivation 1989 (pp. 41-133). Lincoln, NE: University of Nebraska Press.

Uhlmann, E., Dasgupta, N., Elgueta, A., Greenwald, A. G., \& Swanson, J. (2002). Subgroup prejudice based on skin color among Hispanics in the United States and Latin America. Social Cognition, 20(3), 198-226.

Winkelman, M. (1994). Cultural shock and adaptation. Journal of Counseling \& Development, 73(2), 121-126.

Yau, T. Y., Sue, D., \& Hayden, D. (1992). Counseling style preference of international students. Journal of Counseling Psychology, 39(1), 100-104.

Yoon, E., \& Portman, T. A. A. (2004). Critical issues of literature on counseling international students. Journal of Multicultural Counseling and Development, 32(1), 33-44.

MIXALIS POUALKIS, PsyD, received his doctorate in Clinical Psychology from the University of Indianapolis. He currently is an associate professor of psychology at the University of Indianapolis. He teaches both undergraduate and graduate courses and his research focuses on issues of multiculturalism and diversity. Email: poulakism@uindy.edu.

CRAIG A. DIKE, PsyD, received his doctorate in Clinical Psychology from the University of Indianapolis. He currently works for the South Texas Veterans Healthcare System in San Antonio, Texas. Email: dikeca@gmail.com.

AMBER MASSA, B.A., is a doctoral student in the Clinical Psychology program at the University of Indianapolis. Her research and clinical interests include behavioral medicine and healthy psychology, LGBT issues, multicultural issues, and psychological testing. Email: massaa@uindy.edu. 